\title{
The Effect of Using the Guided Discovery Method on Enabling the Students with Intellectual Disability to Acquire some Pre-Academic Mathematical Concepts in the Kingdom of Saudi Arabia
}

\author{
Essam Abdou Ahmed Saleh ${ }^{1}$ \\ ${ }^{1}$ Department of Education, Faculty of Science and Arts, Northern Border University, Rafha, KSA \\ Correspondence: Essam Abdou Ahmed Saleh, Department of Education, Faculty of Science and Arts, Northern \\ Border University, Rafha, KSA. E- mail: dresam1969@yahoo.com
}

Received: December 6, 2017 Accepted: January 3, 2018 Online Published: February 4, 2018

doi:10.5539/ijel.v8n3p108

URL: http://doi.org/10.5539/ijel.v8n3p108

\begin{abstract}
The importance of this study lies in presenting a program to enable the students with mild intellectual disability to acquire some pre-academic mathematical concepts. It also provides a scale to measure the pre-academic mathematical concepts among the educable students with intellectual disability. The study applied the experimental method on a sample of 20 children with intellectual disability who were distributed into two groups; control and experimental. The sample was selected from Rafha Province schools. The program was made up of 96 sessions, four sessions a week. Each session lasted for 60 minutes and was divided into two 30-minute sessions (activities). The researcher used a pre-academic mathematical concepts scale to collect data and to compare the performance of the experimental and control groups in the pre and post-tests. The results of the study indicated that there are statistically significant differences in the pre-academic mathematical concepts scale among the students of the two groups at the (0.01) level in favor of the experimental group.

The improvement in the acquisition of some pre-academic mathematical concepts among the sample members is attributed to the student's utilization of the program used in the current study, which is based on the guided discovery method. The researcher used a group of attractive activities desired by children. The researcher applied number of immediate reinforcements and constant encouragements to enhance proper functioning. He took into consideration presenting these activities in a gradual simplified way, moving from the easy to the hard.
\end{abstract}

Keywords: guided discovery, pre-academic mathematical concepts, students with intellectual disability

\section{Introduction}

The discovering method is considered as one of the teaching methods that enable the child to achieve the actual interaction with activities; so he can acquire different concepts and skills. Ather (1994) referred to the importance of previous experience in interpreting and classifying many ambiguous stimuli.

Sirag (2000) indicated that the guided discovery is one of the teaching strategies, which depends on the learner's activity and the teacher's direction in order to reach the targeted educational goals, in the educational situation. The guided discovery teaching method depends on the problem solving approach which can highly affect the teaching of difficult skills, especially among children since they need to understand the world around them, form different concepts and gain different skills. This could be fulfilled through the direct interaction with items in addition to noticing and discovering their components.

Adopting the guided discovery method is very important in enabling the students with intellectually disabled children to acquire many concepts. Many studies proved that if the child received a good training on the concepts and skills that fit his capacities and potentials, he will be capable of acquiring many skills that will qualify him to live normally and safely in his society.

Enabling the student to acquire the mathematical concepts has a clear pedagogical importance. However, we find that the nature of Mathematics relies heavily on abstracts. According to Jean Piaget's cognitive theory, children belong to the sensorimotor stage that makes them lack the ability to think of abstracts and make it difficult to them to understand the mathematical concepts which are usually taught using weak and ineffective traditional methods. These methods are based on verbal prompting, conning and verbal recalling of the counting and 
number skills. They do not take into consideration the gradual presenting of concepts starting from the basic concepts until reaching the counting and number ones. They also do not suit the nature of child's growth and his cognitive stage in which he needs sensory experience, learning situations and activities. Due to that, such methods cause many problems in constructing process mathematical concepts and lead to the child's poor and lack of comprehension of these concepts in the following educational stages. Unlike normal children, children with intellectual disability of the same age could not acquire the mathematical concepts easily. However, at early age they can achieve success in counting skills, early working with patterns, simple addition and subtraction, solving word problems and developing some concepts such as time and measure. It is possible for children with intellectual disability to join and, to some extent, participate in the normal students regular classes. The curriculum of the students with mild intellectual disability focuses on the basic mathematical skills in addition to the quantum concepts. Thus, there is a substantial difference between any curriculum that targets any category of the students with intellectual disability and the mathematics curriculum of the normal students. In the field of intellectual education, it is found that the maximum level of the child's mental growth does not exceed basic mathematics such as algebra and geometry. Therefore; the experience that enables children with intellectual disability to master the basic mathematical skills and understand the quantum concepts needed in everyday life, must be taken into consideration, when planning a mathematic curriculum for this category.

Alnajdi (2001) confirmed that senses are the windows through which the knowledge and information from the world can be reached and the concepts are formed. Concepts formation about items is based upon wide sensorimotor experience related to different and a various thing. In addition to that, impressions gained through senses about these things are gathered and organized in an overall picture.

Many concepts are formed by children before joining school, especially the concrete concepts learned through dealing with the tangible items or the direct concrete information such as the concepts of, camel, tree, flower, cat, chicken, dove, bird, etc. Children also use symbols or words to refer to these tangible items despite the fact that the word or symbol is not the concept itself, but the concept is the content of the word and what the symbol refers to in the mind of the learner. (Saleh, 2009)

Teaching concepts enables the child to learn useful information about the surrounding environment and connect him directly to the nature where he lives and gain his provision, comfort and luxury. The child enjoys watching the nature which stimulates his imagination with deep thoughts to break the codes of the problems that face him every day. It increases his awareness of the relationships that connect the creatures with each other. It also makes him wants and respects all what is true and realistic in his life and discards the misguided notions and the fallacious opinions.

In addition of being useful by itself teaching mathematical concepts is also useful because it provides children with joy and pleasure no matter what their level, ability, aptitude or degree of maturity is. Mathematical concepts help children to raise questions and think; not only about the targeted activities that helps them to learn, but also about the questions that lead them to the logical thinking. (Saleh, 2009)

The children with intellectual disability are different from the normal children in their mathematical abilities. Their deficiencies in the mathematical thinking is attributed to their inability to understand and solve problems, especially the abstract and word problems in addition to their inability to generalize and move from one mathematical rule to other rules and concepts. The ability of the children with intellectual disability to count without concrete and sensory objects is weak. Therefore, the teacher must develop the mathematical concepts through various activities, games and stories in order not to teach the mathematical concepts in a void space isolated from the daily experience (Yahia \& Obied, 2005).

Khalifa (2006) stressed that the formation of the mathematical concepts by the children with intellectual disability is a very difficult task since the acquisition of the mathematical concepts is a mental process that needs the child to recognize the concept's feature then create its abstract notion. This clarifies the difficulty of forming the mathematical concepts by the children with intellectual disability due to their weak ability to recognize and grasp the abstract concepts.

The process of acquiring the mathematical concepts starts before school. Each concept must be taught to the child in an organized and proficient way before moving to the following stage, otherwise, the gaps will prevent the effective learning and prevent the usage of the skills that will be learned lately. The family and community environments are among the factors that affect the acquisition of the mathematical concepts of the children with intellectual disability. Children with intellectual disability do not possess many of the basic quantum concepts known by the normal child when entering the kindergarten. These concepts are also less mature when joining the special education class for the first time (Crookshank, 1971). 
The researcher makes sure to choose number of the mathematical concepts that suit the sample's abilities and potentials. These concepts are taught using the guided discovery method depending on the researcher's instructions.

\subsection{Problem Statement}

A child with intellectual disability is different than his peer normal child. They are different in terms of the physical, mental, social and emotional aspects. There are differences in the academic aspects too; therefore, the educational or rehabilitative programs and the teaching methods are different between normal and retarded students. Also, the children with intellectual disability, just like the normal ones, go through the cognitive development stages but more slowly. The child with mild intellectual disability moves from the preoperational stage, in which he is able to recognize things using his senses, to the concrete operational stage, in which he can slowly understand the abstract concepts. The reasons behind those students inability to learn is the lack of the correct teaching methods in addition to the fact that they are suffering from problems in memorizing, data receiving and concentrating. Thus, this category of students needs to be cognitively developed through directing, keeping what they have learnt and following a series of steps to move from one stage to another.

Weakness in carrying out the basic mathematical operation is one of the most difficult and common academic problems among children with mild intellectual disability. The main reason behind this weakness is the marked low IQ. This weakness is usually accompanied by an apparent decline in the cognitive abilities, therefore; the strategies used in teaching children with mild intellectual disability differ from the ones used to teach students in regular classes. Thus, the statement problem can be formulated as the following;

What is the effect of using the guided discovery method on the ability of a sample of student's with intellectual disability to acquire some pre-academic mathematical concepts in Rafha province in the Kingdom of Saudi Arabia?

\subsection{The Purpose of the Study}

The purpose of the current study is to introduce a program based on the guided discovery method to enable children with intellectual disability to acquire some pre-academic mathematical concepts (such as the pre-number concepts, classification concepts and order and seriation concepts...etc.). This study aims also at testing the effect of the program and its viability after its end (i.e., during the follow up period).

\subsection{The Significance of the Study}

- The importance of this study is clear in the theoretical perspective as it contributes to the process of enabling children with intellectual disability to acquire some pre-academic mathematical concepts, giving the chance to the designers of the intellectually disabled curriculum to choose the concepts and teach them using different teaching strategies within the curriculum designed for this category. This helps children to adapt with the demands of the daily life and improves their capacities and potentials.

- In practice, the significance of this study lies in focusing on designing a program based on the guided discovery method to develop some mathematical concepts among the children with intellectual disability.

\subsection{The Study Terminology}

- Intellectual Disability: The definition of American Association on Intellectual and Developmental Disabilities (AAIDD): a disability characterized by significant limitations in both intellectual functioning and in adaptive behavior, which covers many everyday social and practical skills. This disability originates before the age of 18. (Legislative Goals, 2008)

- Guided Discovery: One of the important educational methods that depends on providing the learner with stimuli that motivate him to involve in the learning process through the teacher's guidance. This is followed by the learner responses in which he uses some mental processes and previous experience to perform the proper functioning.

- Pre-Academic Mathematical Concepts: A group of notions perceived by senses and can be sorted into categories based on certain known features labeled by a name or a special symbol. It is not only the study of numbers and its patterns, which is known as "counting", but it is the more general term of "mathematics" which is used here.

\subsection{The Study Limitations}

The study sample is composed of 20 children who were distributed into two groups; control (10 children) and experimental (10 children). The sample was selected from Rafha Province schools. The members of the sample 
are 8-11 years old. The members of the sample are homogeneous in terms of gender, age and intelligence.

\subsection{The Study Subject}

The subject of the current study is revealing the effect of applying the guided discovery method in enabling the children with intellectual disability to acquire some pre-academic mathematical concepts, in Rafha province in the Kingdom of Saudi Arabia.

\subsection{The Study Methodology}

Due to the nature of this study, it follows the experimental approach in order to find the effect of using a program based on the guided discovery method (independent variable) in developing the pre-academic mathematical concepts (primary independent variable) among a sample of children with mild intellectual disability.

\subsection{The Theoretical Framework}

\section{Intellectual disability:}

The problem of intellectual disability has a special nature. It is a multidimensional problem which has overlapping different aspects. It is a medical problem that needs a medical interference. Intellectual disability is also an educational problem that needs educational interference to determine the special educational ways and methods. It is considered as a behavioral and psychological problem which demands behavioral treatment to enable the child to adapt with the surrounding community.

The procedural definition of intellectual disability is: "the mild intellectual disability category whose IQ is ranged from 50 to 70 ". This category is educationally defined as "the educable category that usually accompanied by inability to respond to the demands of the daily social life".

\section{The following are some of the mental cognitive features of children with intellectual disability;}

- The tendency to simplify information: those children are characterized by deficiencies in their ability to abstract thinking. They cannot use abstracts in their thinking process and always resort to the usage of concert notions. They have the tendency to define things according to shape or function (the cognitive function), therefore; if one of them is asked about an orange his answer could be edible, round or yellow.

- The teacher of those children is recommended to use three dimension objects and teaching aids (such as; shape, volume and color) in order to enable children to distinguish between them.

- Deficiency in the ability of generalization: as mentioned before, children with intellectual disability have the tendency to simplify concepts and label them according to their functionality, this is because the children have poor sense of generalization, which is a process that requires a certain level of abstraction, for example, a child can answer the question (5+5) giving 10 as an answer while he fails to answer the same question if formed as (5 and 5) since he lacks the ability to recognize the relationship between the mathematical symbols $(+)$ and the conjunction word "and".

- Therefore; the teacher of children with intellectual disability is recommended to put the stimuli in sequence starting from the easy to the difficult. He is also recommended to develop his students' ability to generalize and to take into consideration integrating what is concert with what is abstract during lessons and when dealing with this category.

- Deficiency in recognizing stimuli: the normal child is usually aware of the situations that takes place in front of him or of any stimulus in the surrounding environment. On the other hand, a child with intellectual disability does not pay attention to such situations or stimuli by himself; this is due to his attentive deficit.

- Remembering difficulties and the need of repetition: the previous studies and researches asserted that the intellectually disabled child does not understand the educational situation unless repeated more than once to help him recalling and taking advantage of the educational situation. Hence; it is recommended to apply the principle of "teaching after the completion of teaching".

- Therefore; one can find that repeating what is learnt after being taught is the best way to train a child with intellectual disability on the long term. During the revision process, this method helps the child to connect the educational material with his daily life and enables him to recall these things.

- Weak capacity to use symbols, signs or indirect hints in the educational situations: a child with intellectual disability lacks the ability to pay attention to the educational situation signs and symbols which may guide him to learn and perform the targeted skill. This necessitates that those who are teaching and educating the child must focus, highlight and clarify the elements of the educational situation in a direct and intended way. 
- The lack of the ability to recognize similarities and locate the differences between subjects and situations: it takes certain mental abilities to recognize similarities between the similar subjects and situations and to find out the differences between things. A child with intellectual disability lacks such these abilities.

- Therefore; those who are responsible of educating children with intellectual disability must clarify each educational situation separately and they have to connect the situation with something familiar form the child's environment in order to clearly state the learning objective.

- Low capacity for inference: it is not the remembering difficulties, but the low capacity of inferring is what actually characterizes children with intellectual disability. It is noticed that those children do not tend to use organized strategies in many new situations which leads to storing information in an unorganized way. This is way they find difficulties in solving problems that need thinking and inferring.

- The lack of ability of incidental learning: a normal child can acquire many skills by observation in different situations in his daily life, which is called the "incidental learning". On the contrary, a child with intellectual disability lacks the ability to spontaneously remark gain any skill without training.

- The insufficient ability to take use of experience: the intellectually disabled person faces difficulties in benefiting from what he learnt previously in a new learning activity (this disability is linked with his low capacity of inferring). Therefore; it is recommended to check the educational activities and diverse the learning locations. The learning process must not take place only in the classroom but should be also in other different places in the child's environment. The elements of these places could be used in the educational situations.

- The weak linguistic abilities (linguistic expression): if compared with normal children, the members of this category usually suffer from poor linguistic growth. They are also enable of using lexical items to express their needs and fail to verbally contact others.

- The lack of the ability to imagine and perceive: the intellectually disabled child faces difficulties in imagining places and things and their usages which makes it necessary to exemplify all what we are going to teach, involving all the child's senses in the educational situation. This way the child sees, touches, hears or smells the object according to the situation. (Alhajrasi, 2002; Abdulrasol, 2008)

\section{The interpretation of the intellectual disability in the lights of the cognitive theory:}

Jean Piaget's theory asserts the sequencing and consecutive nature of the individuals' cognitive growth and that they go through different connected stages until reaching a certain level of perfection as a result of the individual's adapting, engaging and interacting with his environment.

Through his observation of the normal child's interacting, adapting and understanding of his environment, he noticed that every child develops by going through several growth stages in which different intellectual skills appear.

1) Sensorimotor stage from the birth to two years old.

2) Pre-operational stage from two to seven years old and divided into two sub-stages:

a. Pre-conceptual sub-stage which occurs between the ages of 2 and 4 .

b. The intuitive thought sub-stage occurs between 4 and 7 .

3) Concrete operational stage which takes place between 7- 11 years old.

4) Formal operational stage.

The following are some of the most important concepts of this theory:

- Assimilation which means the level of the individual understanding of the surrounding environment or the extent he recognizes reality.

- Accommodation which means the level of the individual adaptation with the surrounding environmental circumstances and if he fits into reality.

This theory is important in teaching, choosing and grouping the intellectual disabled children. It also helps in designing their curricula and teaching methods.

Jean Piaget's intelligence test has a significant importance in testing the intellectual disabled children and sorting them in different mental levels. It also plays a vital role in referring them to the specialized academic and curative services. Such tests can reveal the child's aptitude to perform a certain task or to learn a certain course or experience. 
Regarding the curriculum, the internal design of the curriculum and organizing its content in different levels must follow the organization of the cognitive processes in these levels. Which is a very important aspect stated by Piaget's theory.

In regard to teaching methods, Piaget emphasizes the importance of learning through senses and learning by doing in addition to the importance of organizing the work by moving step by step or moving from one level to the more complicated one. This theory certainly provides some applicable concepts and enables the extrapolation in the field of intellectual disability.

\section{The most important basic principles in teaching a child with intellectual disability:}

There are some basic principles that should be considered when developing and preparing any educational program for the intellectual disabled children. These principles facilitate the educational process and achieve better learning in the maximum limits that the child with intellectual disability can reach. These principles are;

1) Do not let the child with intellectual disability fail:

To organize information and use the methods and ways which help the child to reach the right response.

2) Provide the child with direct feedback:

To continuously provide the child with the information needed to recognize his mistakes.

3) Reinforcing the child's right responses:

This means that the reinforcement must be clear and directly connected to the right response in order to enable the child of making a connection between the reinforcement and the response.

4) Determining the best level of the child's performance:

That means the necessity of determining the child's ability in order to specify the best performance that could be reached without asking the child to perform a task that he may fail in.

5) The positive knowledge transition from one situation to another:

To make sure that the child well understands the piece of information before moving to another task.

6) The repetition of the experience provided to the child:

Using repetition in learning develop the children abilities to remember and recall the educational experience and the relations between things. The repetitions must be distributed over certain periods of time.

7) Reducing the number of taught concepts:

The previous studies recommended reducing the amount of information taught to the child, so the child must not be taught any new piece of information unless being certain that he is familiar with the previous one.

8) Organizing the educational material:

This could be done by introducing and carrying out the educational material in an interesting way that draws the child's attention and makes it easier to pay attention to the stimuli that facilitate the educational process.

9) Providing opportunities for the child to succeed:

Due to the fact that the child's self-esteem depends on the extent of his success in the tasks asked to be done by him, the child must be exposed to daily programs that allow him to succeed in short and long term objectives.

10) The teaching process must be carried out on organized and consecutive bases:

The simple tasks must be introduced before the hard ones on the bases of step by step teaching method especially that we deal with a child with limited abilities.

11) Encouraging the child to pay more effort:

The child can be encouraged through; reinforcement, satisfaction felt after success, the diverse variety of educational materials and experience and by teaching for short periods so the child does not get bored. (Alsaid Abdulanbi, 2006)

\section{Guided Discovery:}

Hanafi (2006) indicated that the guided discovery strategy is one of the most important strategies to acquire and learn different concepts. This strategy is based on the scientific thinking that provides learners with an opportunity to discover. The discovery process must take place in appropriate circumstances and under the ongoing guidance of the teacher. 
In general, discovery is finding something which already exists but not known by the discoverer. The discovery process is fulfilled by the good preparation of the educational situation using the appropriate teaching aids and the ongoing guidance which leads finally to the child's acquisition and discovery of information. It also better establishes information in the child's mind. (Muhammed, 2005)

The following are some steps that can be followed by the teacher to design a discovering situation for children with intellectual disability;

1) Specifying the subject that should be discovered in the form of questions or problems presented to the child as puzzling situations to stimulate the child to discover.

2) Identifying the appropriate educational sources and tools to accomplish the discovering situation.

3) Identifying a group of questions and situations to be dealt with by the child. This enables him to discover and reach the main goal (it takes place through encouraging the child to be aware of the relations between things, how they happens, the method of classification ....etc.)

4) Specifying the activities practiced by children (giving applicable examples).

5) Reaching the final result taking advantage of the demonstration provided to him.

6) Repeating the educational situation more than once to enable the child to understand the mentioned piece of information in various ways. (Fawzi, 2002)

\section{The Characteristics of Guided Discovery Learning:}

Proter believes that discovery is the way and the process through which the child gains a new piece of information, which means that discovery includes any mean of knowledge acquisition whereby the child uses his mental or physical resources.

It is a kind of learning that happens as a result of the learner's processing, rearranging and transferring of the information under the guidance of the teacher in order to reach the information indirectly. Thus, the following features of learning by discovering can be listed;

1) Helping the child to learn the process of discovering.

2) Helping in improving the durability of the learning effect and in creating a positive attitude toward the learnt material.

3) Providing an ongoing reinforcement whenever the child is moving ahead one step after another.

4) Reducing forgetfulness among children.

5) Enhancing the child's self-confidence.

6) Transferring the child from being knowledge recipient to knowledge creator.

7) Developing the child's sense of independency and self-reliance.

8) Increasing the actual efficiency of the child.

9) The method is liked by children being an interesting one that thrills the children and draws their attention. (Almajdi, 2001; Alshahrani, 2004)

\section{The Impediments of Guided Discovery:}

Applying the guided discovery method might be faced by some obstacles, such as;

1) The teacher's inability to effectively design and appropriately plan the learning activities.

2) It needs a lot of teaching aids that clarify and support the educational situation.

3) The prolonged period of this method's activities.

4) The big number of subjects which does not fit the lack of time. (Alnajdi, 2003)

\section{Pre-Academic Mathematical Concepts:}

Mathematics is involved in every simple and complicated aspect of our daily life. We simply use it to tell the time and count the change after buying something. We also use it in complicated things such as; processing the house budget and balancing the checkbook. Mathematics is used in cooking, driving, gardening, sewing and many other common activities. It plays a role in many hobbies and sports.

The concept, in mathematics, is an abstract idea that enables people to categorize things and events and decide whether these things and events are examples of the abstract idea or not. For example, the one who learnt the 
concept of triangle can categorize shapes into two sub-groups; triangles or other shapes. A concept can be learnt either by listening, watching, discussing or thinking. (Abuasaad, 2010)

\section{Learning the Pre-Academic Mathematical Concepts by Children with Intellectual Disability:}

Mathematical concepts are some the outcomes of the mental cognitive process. In which abstraction is one of most important features. Therefore; these concepts need a high level of performance to be learnt, especially that they form the basis of mathematics. Due to the fact that children with intellectual disability suffer from an obvious shortage in learning the mathematical concepts, it is important to focus on these concepts and use the latest educational methods in teaching and imparting these concepts to them.

\section{The pre-academic mathematical concepts needed by children with intellectual disability:}

Pre-academic mathematical concepts consist of many complementary components, which are;

1) Pre-number concepts.

2) Classification concepts.

3) Order and seriation concepts.

Each of these components consist of a group of tasks through which children with mild intellectual disability can reach a certain level of distinguishing these concepts and employing them in their behavior and daily life. The first component (Pre-number concepts) aims at enabling the child to differentiate between the following concepts: (big and small), (many and few), (tall and short), (right and left), (up and down), (near and far), (beginning and end), (from and behind) and (inside and outside).

The second component (Classification concepts) includes grouping things according to their common characteristics. Understanding classification and quantities is very important to understand numbers.it usually includes animal pictures, Legos, food pictures or clothes. A child with intellectual disability can establish primary forms of classification when dealing with homogenous tools and toys. The classification experience must be among the primary basics to be provided to the child in order to establish a kind of relationship between him and the concept of group. In order to achieve that, a teacher can ask the students to group different items according to similarity in shape or color.

The classification process includes;

1) Classification according to shape.

2) Classification according to color.

3) Classification according to size.

4) Classification according to direction.

5) Classification according to category

The third component (Order and seriation concepts) means ordering a group of elements in a certain sequence according to certain feature such as; ordering from bigger to smaller or from taller to shorter or vice versa. It is also the ability to order things according to size, taste, color, length or sound in ascending or descending order.

With the growth of the classification ability, the ability to create ordering and series also grows. The experiences conducted upon children focused on creating sequences. The children were given different items that vary in length and were asked to order them according to the length variable. The results reveal that children are able to naturally perform simple and multiple- sequencing.

Sequence includes;

1) Sequence according to length.

2) Sequence according to size.

\subsection{Literature Review}

The researcher reviewed a couple of studies that tackle the mathematical concepts and how normal students and students with intellectual disability learnt them using the guided discovery method.

Kroesbergen \& Van Luit (2003) conducted a study asserted the importance of using the problem solving strategy to learn the principles and basic skills of mathematics by children with intellectual disability. The results also showed the importance of the learning duration and the necessity of self-learning since it is considered the most effective method. It also confirmed the role of computer in learning the basic mathematical concepts. 
Thurlow \& Turnure (2003) also confirmed in a study conducted on a sample of ordinary and intellectually disabled children that children with intellectual disability can learn some mathematical concepts, i.e. concepts of time and money.

On the other hand, Milo, Seegers, Ruijssenaars, \& Vermeer (2004) study, which tackled the way of dealing with children with intellectual disability when learning mathematical concepts, asked whether to guide instruction or direct it. The study investigated two types of children with special needs, students with intellectual disability and students with specific learning disabilities. During the process of learning how to add, subtract and count up to 100. The study aimed at investigating the emotional effects of the two types using two methods; guided self-learning and ongoing directed instructing by teachers. The study showed that the learning quality outcomes of the two methods are different.

The target of Clements's study (2005) was to ensure that when children learn the mathematical skills through the demonstrative tools, they become more creative and successful. The study was conducted on three groups of children from 3-5 years old. The first members of the first group were asked, under guidance, to replace items with sticks of the same number. The children in the second group were allowed to play with sticks and make connections between them while the members of the third group were prohibited from playing and deprived from previous learning. The results clarified that performance of the first two groups was better than the performance of the third one, which asserts the importance of using different activities and demonstrative tools in teaching abstract skills.

In his research, Itzhak (2006) aimed at (a) finding out the effects of using multi-media in learning mathematics and how it affects the mathematical performance of the kindergarten children and (b) testing the children level of acceptability to learn these skills using computer. The study targeted a sample of 116 children, divided into three groups. The first group was trained on mathematical skills using computers in cooperative groups, the second group received the same training but individually while the third group did not receive any training. The results showed that the children's performance in the first two groups was much better than the performance of the third one. This indicates that teaching these skills using different assisting ways can better develop them.

Nilley Alatar (2006) referred, in her study, to the role of music activities in enhancing the kindergarten child's ability to understand some mathematical concepts that must be acquired in this stage. These concepts form the basis of preparing children to mathematics. They pave the way for understanding the content of mathematics in the following educational stages. This helps the child to know the basics of problem solving and to understand the world around him in a way that enables him to successfully deal with mathematics during his academic life. In addition to being considered as a strong support to the child's awareness of the surrounded nature. These concepts are not only important in learning the mathematical concepts in the following stages but also to learn and facilitate other subjects. Studying mathematics dose not contribute only in assisting the child to understand the basic skills of counting, measuring, information organizing and interpreting, concluding, problem solving, assumptions formulating, assumptions proving and assumptions predicting, but contributes also in raising the questions that stimulate children to think during the different educational activities and reach the answer while thinking.

The study of Ortega-Tudela \& Gómez-Ariza (2006) asserted the importance of the role of computers in learning mathematics by children with Down syndrome. The efficiency of multi-media teaching method and the efficiency of the traditional teaching method (using pen and paper) were compared when teaching the concepts of number and the basic relations between the mathematical concepts. The study clarified the efficiency of the multi-media teaching method in enabling children with Down syndrome to learn mathematics. "D. S"

Kristen's study (2007) discussed the mathematical skills among children with Down syndrome. These skills were tested by the "Test of Early Mathematics Ability (TEMA-z)", which examines a various number of skills; such as the verbal abilities and the number line skills. The study sample was formed out of 28 male and female children; 14 with Down syndrome and 14 normal children. The results indicated the existence of differences in the responses of the two groups and that the responses of the children with Down syndrome were more than expected. In addition to that, the results proved that those children have a very high ability to read numbers, which may reach the level of the normal child's ability. This indicates that the verbal mathematical skills among children with Down syndrome are higher than the written ones.

Kristen (2007) also conducted a study about the mathematical skills among children with Down syndrome. These skills were examined by the "Test of Early Mathematics Ability (TEMA-z)", which tests many skills; such as the verbal abilities and the number line skills. The study sample was formed out of 28 male and female children; 14 with Down syndrome and 14 normal children. The results indicated the existence of differences in 
the responses of the two groups and that the responses of the children with Down syndrome were more than expected. In addition to that, the results proved that those children have a very high ability to read numbers, which may reach the level of the normal child's ability. This indicates that the verbal mathematical skills among children with Down syndrome are higher than the written skills. It is also proved that the performance level of those children reaches the level of the normal children at the age of three or four.

The results of Marwa Sulaiman's study (2007), “a Program to Enable the Normal Students and Students with Hearing Impairment in Kindergarten to Acquire Some Mathematical Concepts through Programs that Develop these Con0cepts" stressed the importance of activities in the life of both normal and hearing-impaired students. These activities could be used in personal development of children and in the indirect ways of learning. In his study about the advantages of using games to develop the mathematical skills among a sample of normal and disabled children.

Cavanagh (2008) aimed at finding out the extent of their awareness of the concept of number and its meaning. The study used a sample of 124 children divided into two groups; (normal children and disabled children of older age). Each session or game lasts between 15-20 minutes for two consecutive weeks. The following are some of the suggested games in this study; the traditional board game "Sija", moving the numbered squires game, the snakes and ladders game, etc. Children were allowed to repeat the same game for four times in the same session. The results of this study showed an improvement in the knowledge of the normal and disabled children in four different areas related to numerical sense (name, shape, meaning and written digits). This indicates that children with intellectual disability can comprehend some of the mathematical skills if taught through a group of repeated activities.

The target of David's study (2008) was to test the degree of using the counting skills in completing purchases. A new strategy called the "Next Dollar" was applied on a sample of 6 Autistic children for six consecutive weeks. The children were trained on the simple adding and subtracting operations during purchases. The children were first taught to count from 1 to 5 then to count to 10 , after this, the process was transformed into the form of invoices in purchases. The child used to receive a verbal reward when answering correctly and was allowed to try for two consecutive times if he failed. The study results revealed a clear improvement in the children's mathematical skills when used in purchasing. The results also showed that the effects last for more than six weeks.

UIF Andersson (2008) tried in his study to find out the level of mathematical competence of children with learning difficulties. The mathematical performance of 182 was examined. The children were divided into four achievement groups: children with mathematic difficulties, children with both mathematic and reading difficulties, children with reading difficulties and normally achieving children. All groups performed worse than the last one in all but one area, the place value knowledge, in which they performed equally. The study recommended to pay more attention to the continues training of the children with learning difficulties on the special skills of mathematic, reading and writing in order to enable them to reach the appropriate educational level.

The study of Emad Sama'an (2009) clarified that there are many ways to teach numbers such as; induction, deduction, discussion and educational games on computers. There is no way to decide if there is a method better than the other. The teacher can prepare children for understanding the concept of the number before learning the direct and indirect adding and subtracting operations. The teacher can use the educational games to directly teach the basic facts and concepts of numbers, by presenting each concept in the form of a real problem through these games. This process leaves the children in front of a problem that challenges their abilities and motivates them to compete with other players to solve it.

Nivien Mories Fahiem (2010) aimed at structuring a recreational motor program to develop the numerical skills and general motor growth among the intellectually disabled children aged from 9-14. It also aimed at finding out the effects of this program on;

a. The numbers' forms and concepts.

b. General motor development and its representations in the transitional movements and the performance control skills.

The study concluded that the recreational motor program affects the numerical skills in terms of forms and concepts in addition to its impact on the general motor growth skills.

Abeer Mohammed (2012) asserted on the efficiency of a program based on the concept of integration in developing the manual printing techniques and the academic achievement in mathematics among the educable 
intellectually disabled students. The study tackled the preparation and design of the units and programs of art and special education. It investigated the studies which are relied on applying the integration method between the educational fields and the ones interested in the elements and bases of the printing design and manual printing. The study also discussed the characteristics of the intellectually disabled students, their rehabilitation and welfare curricula, their individual features, their general growth aspects, the role of their art teacher and the characteristics of their art. In addition to that the study discussed the working methods of the manual printing "Stencil Printing" and its templates, tools, row materials, steps, advantages and disadvantages.

The study of Jabir Eisa (2013), about the efficiency of a training program, confirmed some mathematical concepts (classification/ seriation/ One-to-one correspondence) among a sample of children with mild intellectual disability. The study compared their performance with the performance of a group of children of the same mental age. The study concluded that after training children with mild intellectual disability, no differences were found between the two groups regarding the concepts of (classification/ seriation/ one-to-one correspondence), which confirmed that those children can learn such concepts just like the ordinary children who are of the same mental age despite the fact that they need more time and effort.

Maha Abdulhamied (2013) aimed in her study to recognize the effect of applying educational games on developing some mathematical concepts among the talented children with developmental learning disabilities and their effect on reducing the impact of learning disabilities among the talented children. The study also aimed at verifying the durability of the effects of using educational games on developing some mathematical concepts among the talented children with developmental learning disabilities and verifying the durability of the effects of these games on reducing the impact of learning disabilities among the talented children.

Iliev \& D'Angelo (2014) aimed at studying the efficiency of using children's literature as a way or method of developing the child's mathematical concepts. Listening to stories and looking at their lines and draws help to develop the child's curiosity. Among the mathematical concepts that could be learnt through stories is the concept of number, since the teacher can loudly read the story changing its creatures into numbers and thus the lively story turns to be an educational tool to learn some of the mathematical concepts.

The study of Dejonckheere, Desoete, Fonck, Roderiguez, Leen, Vermeersch, \& Vermeulen (2014) highlighted the role of "Sensory-Motor" games in developing the children's mathematical concepts. The study asserted the role of physical and action shows in developing these concepts. Regarding the relationship between integrating children with intellectual disability and normal students when learning some problem solving and mathematical concepts, the study clarified that integrated children with intellectual disability acquired some concepts related to ratios and geometry.

Iliada \& Evangelou (2014) asserted the importance of non-verbal gestures in learning the spatial concepts among children. The study was based on the verbal and non-verbal behavioral in learning the spatial concepts "in- outinside- under- on- beneath". It used some non-verbal gestures to help children to understand the spatial concepts which used to be abstract and not represented appropriately by pronunciation and verbal expression.

\section{A Comment on the Previous Studies:}

- After reviewing the previous literature, the researcher presents how he benefited from these studies. The researcher took advantage of these studies to determine the purpose of his study, choose the tools, design the scale, select the sample and form hypotheses. Some of the previous research papers stressed the efficiency of early intervention programs and activities for children with intellectual disability, the extent of their ability to develop the different growth aspects of those children, in addition to the basic skills needed by those children. Other studies focused on mathematics for children with intellectual disability using guided learning to develop some mathematical concepts (size/ length/ weight) among children with intellectual disability in kindergarten.

- The development of mathematical concepts through playing, stories, etc. is a very important issue in order not to teach these concepts in isolation from the daily experience. It is also important to make sure that the process of teaching mathematics and related concepts has value and many benefits in the daily life of the intellectually disabled child. This process must grow with the child which means that the process must develop from easy to difficult. In addition to that, the children with intellectual disability must have the chance to use the mathematical concepts in meaningful practical situations that provide them with the basic skills in order to be able to involve in the social and professional daily life.

- The previous studies tackled the ways and methods that develop the mathematical concepts among the normal children in general, and children with intellectual disability in specific. Some studies were interested in the daily experience, its role in developing the mathematical concepts and its importance in developing these 
concepts among the children with intellectual disability. Other studies attributed the improvement of the intellectually disabled children's pre-academic mathematical skills to the technics, methods, activities and computer programs used in teaching and developing their mathematical skills. These skills contributed to the modification and enhancement of the adaptive behavior of children with intellectual disability. The used computer program was based on behavioral tools such as; reinforcement, modeling, simulation and feedback. It employed most of the child's senses. In addition to that, some tangible items from the children's daily life such as; clothes, chairs, toys, gloves, balls, shapes...etc. were employed to modify and enhance their adaptive behavior.

\subsection{The Study Hypotheses}

Within the theoretical frame, the literature review and the results of the previous studies, the study hypotheses can be formulated as the following;

- There are statistically significant differences between the rank correlation means of the children of the experimental group in the pre- test and post-test in terms of the pre-academic mathematical concepts in favor of the post-test.

- There are statistically significant differences between the rank correlation means of the children of the experimental and control groups in the post-test in terms of the pre-academic mathematical concepts in favor of the experimental group.

- There are no statistically significant differences between the rank correlation means of the children of the experimental group in the post test and the follow up test (conducted after a month) in terms of the pre-academic mathematical concepts.

\section{Method}

\subsection{Study Method}

Due to the fact that the current study is based on conducting a program that enables children with intellectual disability to acquire some pre-academic mathematical concepts, the researcher used the experimental method. The researcher selected a homogeneous sample of 20 children similar in terms of age, intelligence and level of awareness of the pre-academic mathematical concepts before applying the program. All the sample members participated in the programs activities.

The following table illustrates the data of the study samples

Table 1 . The study sample distribution

\begin{tabular}{llll}
\hline Sample & Gender & Total Number \\
\hline Experimental Group & 5 & 5 & 10 \\
Control Group & 8 & 2 & 10 \\
Total Number & 13 & 7 & 20 \\
\hline
\end{tabular}

Table 2. The homogeneity of the sample in terms of age and the significance of the difference between the experimental and control groups regarding the age variable

\begin{tabular}{lllllll}
\hline Variable & Group & $\mathrm{N}$ & Mean Rank & Sum of ranks & Z Value & Level of Significance \\
\hline \multirow{2}{*}{ Age } & Control & 10 & 9.15 & 91.50 & \multirow{2}{*}{0.3} & \multirow{2}{*}{ Not Significant } \\
& Experimental & 10 & 11.85 & 118.50 & & \\
\hline
\end{tabular}

\section{Intelligence Quotient:}

The researcher applied the "Draw-a-Person" test (prepared by Goodenough and Harris) on the study sample. The IQ of the sample ranged from 52 to 73 points. The following table illustrates the homogeneity between the two groups in terms of intelligence quotient. 
Table 3. The homogeneity between the sample's members in terms of IQ and the significance of the difference between the experimental and control groups regarding the intelligence variable

\begin{tabular}{lllllll}
\hline Variable & Group & $\mathrm{N}$ & Mean Rank & Sum of ranks & Z Value & Level of Significance \\
\hline \multirow{2}{*}{ Age } & Control & 10 & 9.50 & 95.00 & \multirow{2}{*}{0.44} & \multirow{2}{*}{ Not Significant } \\
& Experimental & 10 & 11.50 & 115.00 & & \\
\hline
\end{tabular}

The previous table shows that there are no statistically significant differences between the children of the experimental and control groups regarding the intelligence variable, due to the insignificant effect of $Z$ value in terms of the intelligence variable.

\subsection{Research Procedure}

To conduct the study, the researcher followed these steps;

1) Having access to the files of all the students registered in the "Intellectual Schools" in Rafha, whose age ranged from 8 to 11 years and IQ from 52-73 points.

2) Interviewing some teachers and parents to collect data about the intellectually disabled child's level of understanding of some pre-academic mathematical concepts presented during teaching. This is done to prepare a scale to measure the pre- academic mathematical concepts among children with intellectual disability.

3) Designing a training program based on the guided discovery learning method to enable children with intellectual disability to acquire some pre- academic mathematical concepts.

4) Selecting the sample and homogenizing it.

5) Running the pre-test to measure the pre-academic mathematical concepts among the sample members.

6) Applying the training program which is based on the guided discovery learning method upon the study sample.

7) Conducting the post test on the children of the study sample.

8) Applying the follow-up test a month after the study ends (applied by the researcher).

9) Drawing conclusions by the researcher using the appropriate statistical methods.

10) Explaining the study results in the light of the theoretical framework and the previous literature.

\subsection{The Study Tools}

The researcher used the following tools:

1) Goodenough and Harris intelligence test.

2) The pre-academic mathematical concepts scale. (Designed by the researcher).

3) A program based on guided discovery to enable the children with intellectual disabilities to acquire some pre-academic mathematical concepts. (Designed by the researcher).

The following is a description of each of these tools,

\section{The pre-academic mathematical concepts scale (Designed by the researcher).}

The researcher applied the pre-academic mathematical concepts scale (Designed by the researcher) on a sample of children with mild intellectual disability in order to homogenize between the children of the two groups (the control and the experimental) in terms of the extent of understanding the pre-academic mathematical concepts, separately for each component. This scale is distinguished because the researcher applied it upon the child himself. It also investigated the pre-academic mathematical concepts through the actual direct responses of the child. The child himself answers the questions of this scale. The following table illustrates the homogeneity between the two groups in terms of their understanding of the pre-academic mathematical concepts:

The researcher used Mann-Whitney test to find out the significance of the difference between the two groups.

The following table illustrates the results concluded by the researcher; 
Table 4. The significance of the differences between the mean ranks of the experimental and control groups regarding the pre-academic mathematical concepts, before applying the program

\begin{tabular}{lllllll}
\hline Dimensions & Group & $\mathrm{N}$ & Mean Rank & Sum of ranks & Z Value & Level of Significance \\
\hline \multirow{2}{*}{ First } & Control & 10 & 8.35 & 83.50 & \multirow{2}{*}{1.69} & \multirow{2}{*}{ Not Significant } \\
& Experimental & 10 & 11.50 & 126.50 & & \\
\multirow{3}{*}{ Second } & Control & 10 & 11.40 & 114.00 & \multirow{2}{*}{0.7} & Not Significant \\
& Experimental & 10 & 9.60 & 96.00 & & \\
\multirow{3}{*}{ Fird } & Control & 10 & 11.9 & 119.00 & \multirow{2}{*}{1.24} & \multirow{2}{*}{ Not Significant } \\
& Experimental & 10 & 9.10 & 91.00 & & \multirow{2}{*}{ Not Significant } \\
& Control & 10 & 10.80 & 108.00 & \multirow{2}{*}{0.23} & \\
\hline
\end{tabular}

The previous table clarifies that there are no statistically significant differences between the experimental and control groups on the scale's dimensions and its total mark. This indicates the homogeneity between the members of the two groups in terms of the scale's dimensions and its total mark.

\section{The Scale's Description:}

The scale is composed in its final version of (27) articles that suit children with mild intellectual disability aged from 8 to 11 years. The scale was designed to be applied upon the child himself without relying on the points of view of his teacher, father or mother. The tasks or articles of the scale were distributed according to its three components;

The first component: pre-number concepts.

The second component: classification concepts.

The third component: order and seriation concepts.

\section{The Scales Validity:}

The arbitrators' validity: the researcher measured the scale's validity by consulting six education and psychology arbitrators specialized in the field of education and disability. The agreement percentage between them is $94.25 \%$.

\section{The Test Reliability:}

The researcher found out the test reliability using (Test-Retest Reliability and Split-Half Reliability).

In the Test-Retest reliability the same scale was applied twice with a time lag of two weeks. The correlation is $(0.842)$ and the reliability is $(0.994)$.

The reliability was also calculated using Split-Half reliability which value was (0.994) using Pearson correlation coefficient.

\section{Research Procedure:}

The researcher conducted the pre-test then it was conducted again after running the educational program.

\section{A Program Based on the Guided Discovery Method to Allow Students with Intellectual Disability to Acquire Some Pre-Academic Mathematical Concepts}

\subsection{The Purpose of the Study}

The program used in the current study aims at enabling children to acquire some pre-academic mathematical concepts. These concepts are positively reflected on the student's behavior and the way he deals with things around him. They help him to recognize and differentiate between directions. They also help in knowing numbers, their figures and how to deal with them. In addition to that, they enable the child to use the classification process to sort different items around him.

The following is a brief description of the program component;

\section{The program goals;}

- The program aims at fulfilling the following general and procedural goals:

- The program general goals (main objectives):

- The first component: pre-number concepts.

- The second component: classification concepts. 
- The third component: order and seriation concepts.

The program's main objective is to enable children with mild intellectual disability to acquire some pre-academic mathematical concepts.

\section{The program's procedural goals:}

1) To inform and train children on the following pre-number concepts;

Big- Small.

Many- Few.

Tall- Short.

Right- Left.

Up- Down.

Near- Far.

Start- Finish.

Front- Behind.

In- Out.

2) To apply the previous pre-number concepts indifferent life situations.

3) To inform and train children on the following classification concepts;

- Classification according to shape.

- Classification according to color.

- Classification according to size.

- Classification according to direction.

- Classification according to category.

4) To apply the previous classification concepts in different life situations.

5) To inform and train children on the following order and seriation concepts;

- Seriation according to length.

- $\quad$ Seriation according to size.

6) To apply the previous classification concepts in different life situations.

\subsection{The Content of the Program}

- The educational content of the program is based on the fundamental domains and dimensions referred to by the previous studies.

- The program relies on a group of activities, such as; mental activities, motor activities, story activities and artistic activities.

\subsection{The Program's Session}

The program is divided into sessions. It lasts for three consecutive months, four sessions a week. The duration of each session is 60 minutes, divided into two 30 minutes sessions/ activities. There is a rest period between the two activities excluded from the total time of the session.

According to this, the total number of sessions in this program is 96 divided into 24 sessions related to mental activities, 24 sessions related to motor activities, 24 sessions related to story activities and 24 sessions related to artistic activities. The sessions were distributed alternatively depending on the three components of the study.

Table 5. The sessions' distribution

\begin{tabular}{ll}
\hline Sessions & \\
\hline First Session & Introductory and opening session \\
Sessions two to the thirty two & Pre-number concepts \\
Sessions thirty three to sixty four & Classification concepts \\
Sessions sixty five to ninety five & Seriation and order concepts \\
Session ninety six & Closing session \\
\hline
\end{tabular}




\subsection{The Program's Most Important Principles and Fundamentals}

1) The activities meet the needs and suit the ability of the child with intellectual disability.

2) The activities are familiar, which means that all the activities' tools are from the children's environment.

3) The activities and their tools.

4) Good organization and appropriate preparation before each activity.

5) The necessary reinforcement during and after each activity.

6) Diverse types of reinforcement.

7) The role of the teacher, child and researcher must be determined.

8) Gradual presentation of the concepts.

9) Determining the guidance way used by the teacher and the researcher, taking into consideration using different ways according to the activity.

10) Observance of the continuous repetition of the activities and information provided to child.

11) Paying attention to the elements of attraction and suspense while presenting the activity.

12) Determining the appropriate timing for the child to finish the required task. After this period, the intervention of the teacher or the researcher is required. (Abdullah, 2007)

\subsection{The Techniques Used in the Program}

\section{(1). Guided Discovery:}

Using the guided discovery method in teaching children with intellectual disability the pre-academic mathematical concepts is very important as it helps them to actually practice the content of the concept and try to figure out the right solution to find the right answer under the guidance of those who help him to reach the correct answer. Thus, this educational method becomes the best method since it stimulates the child to discover the answer by himself.

Through discovery, children acquire the concepts, skills, information and the items related to their world. Discovery, whether by trial and error or the direct and indirect guidance, is an educational objective in itself. (Haugland, 2000)

\section{(2). Reinforcement:}

It is the process that follows immediately the right response and encourages the child after practicing the right behavior. It increases the probability of having the same response when the same situation occurs again in the future (Alqathafi, 2001).

\subsection{The Study Variables}

The current study consists of the following variables:

1) The independent variable :( the program based on guided discovery).

2) The dependent variable :( pre-academic mathematical concepts for the children with intellectual disability).

\subsection{The Tools and Teaching Aids Used in the Program}

Many tools and teaching aids were used to carry out the program's activities, such as;

- Raw materials, tools and items that help in creating the suggested teaching aids:

1) Teaching aids for art activities: (papers, crayons, raw material, cereals, adhesive tapes ...etc.).

2) Teaching aids for motor activities: (hula hoop, ropes, balls of different sizes and colors, chairs of different sizes ...etc.)

3) Teaching aids for mental activities: (cubes of different sizes and colors, puzzles... etc.)

4) Teaching aids for stories activities: (comic books, stories, spiral notebook, puppet theatre...etc.)

5) Some movies and audio records.

\subsection{The Program Evaluation}

The researcher made sure the evaluation process is conducted in several stages as the following; 
1) Phase Evaluation: it takes place during the application of the activities which are based on the guided discovery learning method. This is the basis of the program because it depends on guiding the child to the right behavior not the wrong one.

2) Final Evaluation: it is applied immediately after the end of the program (post-applied). The scale of the pre-academic mathematical concepts for children with intellectual disability is applied on the study sample.

3) Follow-up Evaluation: it is conducted by applying the scale of the pre-academic mathematical concepts for the children with intellectual disability after one month. It is applied in order to check the efficiency of the program which is based on the guided discovery to develop some pre-academic mathematical concepts among the children with intellectual disability.

\subsection{The Statistical Methods}

The researcher used some appropriate statistical methods in the study;

1) Wilcoxon test to find out the significant differences between the related groups.

2) Mann-Whitney test to discover the significant differences between the two independent groups.

3) Arithmetic mean.

4) Standard deviation.

\section{Research Procedure}

The researcher conducted the current study following these steps;

1) The scientific material, (such as; books, articles, studies, etc.), was collected in order to fully construct the theoretical framework of the study.

2) The researcher prepared a primary data format about the children of the sample.

3) Designing the scale of the pre-academic mathematical concepts for the children with intellectual disability and verifying its validity and reliability.

4) The study sample was selected and divided into two groups; experimental and control.

5) The researcher homogenized the members of the two groups in terms of age, IQ and the extent of understanding the pre-academic mathematical concepts.

6) A pre-test was conducted upon the two groups (experimental and control) through applying the scale of pre-academic mathematical concepts of the children with mild intellectual disability (designed by the researcher) in the preparation phase.

7) Applying the pre-academic mathematical concepts' acquisition program on the members of the experimental groups.

8) The current program was applied upon the children with mild intellectual disability during the first semester of the academic year 2017-2018.

9) Conducting the post-test on the two groups (experimental and control) through applying the scale of the pre-academic mathematical concepts of the children with mild intellectual disability (designed by the researcher).

10) Conducting the follow-up test on the experimental group after one month of applying the post-test in order to find out the durability of the program's effect on the study sample.

11) Statistically processing data using the appropriate statistical methods.

12) Presenting, discussing and interpreting the results.

13) Drawing the educational recommendations related to the subject of the study.

\section{Results and Discussion}

The current study aims at finding out the effect of using the guided discovery method on enabling the students with intellectual disability to acquire some pre-academic mathematical concepts in Rafha Province in the Kingdom of Saudi Arabia.

\section{First: the study results:}

The study results can be presented according to the study hypotheses as following; 


\subsection{The Results of the First Hypothesis}

The first hypothesis states that: there are statistically significant differences between the rank correlation means of the children of the experimental group in the pre- test and post-test in terms of the pre-academic mathematical concepts in favor of the post-test.

To verify this hypothesis, the researcher used the Wilcoxon test to find out the significant differences between the two tests. The following table shows what the researcher concluded in this regard.

Table 6 . The existence of statistically significant differences between the rank correlation means of the children of the experimental group before and after applying the pre- and post-tests on the pre-academic mathematical concept's scale

\begin{tabular}{|c|c|c|c|c|c|c|}
\hline Dimension & The results & $\mathrm{N}$ & Mean Rank & Sum of ranks & Z Value & Level of Significance \\
\hline \multirow[t]{4}{*}{ First } & Negative ranks & 0 & & & & Significant at the 0.01 level \\
\hline & Positive ranks & 10 & 0 & 0 & & \\
\hline & Ties & 0 & 5.50 & 55 & 2.81 & \\
\hline & Total & 10 & & & & \\
\hline \multirow[t]{4}{*}{ Second } & Negative ranks & 0 & & & & Significant at the 0.01 level \\
\hline & Positive ranks & 10 & 0 & 0 & & \\
\hline & Ties & 0 & 5.50 & 55 & 2.814 & \\
\hline & Total & 10 & & & & \\
\hline \multirow[t]{4}{*}{ Third } & Negative ranks & 0 & & & & Significant at the 0.01 level \\
\hline & Positive ranks & 10 & 0 & 0 & & \\
\hline & Ties & 0 & 5.50 & 55 & 2.814 & \\
\hline & Total & 10 & & & & \\
\hline \multirow[t]{4}{*}{ Total } & Negative ranks & 0 & & & & Significant at the 0.01 level \\
\hline & Positive ranks & 10 & 0 & 0 & & \\
\hline & Ties & 0 & 5.50 & 55 & 2.812 & \\
\hline & Total & 10 & & & & \\
\hline
\end{tabular}

The previous table illustrates the existence of statistically significant differences between the rank correlation means of the children of the experimental group before and after applying the program on the first dimension, where $\mathrm{Z}$ value $=2.81$ which is statistically significant at the 0.01 level in favor of the post-test. The table also clarifies that there are statistically significant differences between the rank correlation means of the children of the experimental group before and after applying the program on the second dimension, where $\mathrm{Z}$ value $=2.814$ which is statistically significant at the 0.01 level in favor of the post-test. Statistically significant differences are found between the rank correlation means of the children of the experimental group before and after applying the program on the third dimension, where $\mathrm{Z}$ value $=2.814$ which is statistically significant at the 0.01 level in favor of the post-test. There are also some statistically significant differences between the rank correlation means of the children of the experimental group before and after applying the program on the total mark, where $\mathrm{Z}$ value $=2.812$ which is statistically significant at the 0.01 level in favor of the post-test.

\subsection{The Results of the Second Hypothesis}

The second hypothesis states that there are statistically significant differences between the rank correlation means of the children of the experimental and control groups in the post-test in terms of the pre-academic mathematical concepts in favor of the experimental group.

To check this, the researcher applied the Wilcoxon test to find out the significant differences between the children of the two groups.

The following table illustrates what the researcher concluded in this regard. 
Table 7. The significant differences between the rank correlation means of the children of the experimental and control groups after applying the program on the pre-academic mathematical concept's scale

\begin{tabular}{lllllll}
\hline Dimension & Group & $\mathrm{N}$ & Mean Rank & Sum of ranks & Z Value & Level of Significance \\
\hline First & Control & 10 & 5.50 & 55 & \multirow{2}{*}{3.83} & Significant at the 0.01 \\
& Experimental & 10 & 15.50 & 155 & & level \\
Second & Control & 10 & 5.50 & 55 & 3.84 & Significant at the 0.01 \\
& Experimental & 10 & 15.50 & 155 & & level \\
& Control & 10 & 5.50 & 55 & 3.87 & Significant at the 0.01 \\
\multirow{3}{*}{ Third } & Experimental & 10 & 15.50 & 155 & & level \\
& Control & 10 & 5.50 & 55 & 3.79 & Significant at the 0.01 \\
& Experimental & 10 & 15.50 & 155 & level \\
\hline
\end{tabular}

It is clear from the previous table that there are statistically significant differences between the rank correlation means of the children of the experimental and control groups after applying the program on the first dimension, where $Z$ value $=3.83$ which is statistically significant at the 0.01 level in favor of the experimental group. In addition to that, the table shows the existence of significant differences between the rank correlation means of the children of the experimental and control groups after applying the program on the second dimension, where $\mathrm{Z}$ value $=3.84$ which is statistically significant at the 0.01 level in favor of the experimental group. It also shows the existence of significant differences between the rank correlation means of the children of the experimental and control groups after applying the program on the third dimension, where $\mathrm{Z}$ value $=3.87$ which is statistically significant at the 0.01 level in favor of the experimental group. There are also statistically significant differences between the rank correlation means of the children of the experimental and control groups after applying the program on the total mark, where $Z$ value $=3.79$ which is statistically significant at the 0.01 level in favor of the experimental group.

\subsection{The Results of the Third Hypothesis}

The third hypothesis states that there are no statistically significant differences between the rank correlation means of the children of the experimental group in the post test and the follow up test (conducted after a month) on the pre-academic mathematical concept's scale.

To verify this hypothesis, the researcher applied the Wilcoxon test to investigate the significant differences between the two tests. The following table illustrates what the researcher concluded in this regard.

Table 8. The significant differences between the rank correlation means of the children of the experimental group in the post and follow up tests on the pre-academic mathematical concept's scale

\begin{tabular}{|c|c|c|c|c|c|c|}
\hline Dimension & The results & $\mathrm{N}$ & Mean Rank & Sum of ranks & $Z$ Value & Level of Significance \\
\hline \multirow[t]{4}{*}{ First } & Negative ranks & 4 & & & & Not significant \\
\hline & Positive ranks & 1 & 2.63 & 10.50 & & \\
\hline & Ties & 5 & 4.50 & 4.50 & 0.82 & \\
\hline & Total & 10 & & & & \\
\hline \multirow[t]{4}{*}{ Second } & Negative ranks & 2 & & & & Not significant \\
\hline & Positive ranks & 2 & 3.00 & 6.00 & & \\
\hline & Ties & 6 & 2.00 & 4.00 & 0.37 & \\
\hline & Total & 10 & & & & \\
\hline \multirow[t]{4}{*}{ Third } & Negative ranks & 1 & & & & Not significant \\
\hline & Positive ranks & 1 & 2.00 & 2.00 & & \\
\hline & Ties & 8 & 1.00 & 1.00 & 0.44 & \\
\hline & Total & 10 & & & & \\
\hline \multirow[t]{4}{*}{ Total } & Negative ranks & 4 & & & & Not significant \\
\hline & Positive ranks & 2 & 3.63 & 14.50 & 0.85 & \\
\hline & Ties & 4 & 3.25 & 6.50 & & \\
\hline & Total & 10 & & & & \\
\hline
\end{tabular}

The previous table illustrates that there are no statistically significant differences between the rank correlation means of the children of the experimental group in the post and follow-up tests on the first dimension, where $\mathrm{Z}$ value $=0.82$ which is not statistically significant. The table also clarifies that there are no statistically significant differences between the rank correlation means of the children of the experimental group in the post and 
follow-up tests on the second dimension, where $\mathrm{Z}$ value $=0.37$ which has no statistical significance .No statistically significant differences are found between the rank correlation means of the children of the experimental group in the post and follow-up tests on the third dimension, where $Z$ value $=0.44$ which is not statistically significant. Also, there are no statistically significant differences between the rank correlation means of the children of the experimental group in the post and follow-up tests on the total mark, where $\mathrm{Z}$ value $=0.85$ which is not statistically significant.

\section{Discussion and Interpretation}

The study results prove the hypotheses and indicate that the acquisition of some pre-academic mathematical concepts by children with intellectual disability (study sample) is improved. This improvement can be attributed to the fact that those children benefited from the program which is based on the guided discovery learning method that is used in the current study. The researcher used a group of attractive activities desired by children. He applied number of immediate reinforcements and constant encouragements for the children's proper functioning. The researcher took into consideration presenting these activities in a gradual simplified way, moving from the easy to the hard. He also took into consideration the necessity of repeating some activities in order to be certain that each child in the sample acquires the presented concept.

The analysis of the third hypothesis shows that there are no statistically significant differences between the rank correlation means of the children (the sample) in the post and follow-up tests in terms of the acquisition of the pre-academic mathematical concepts. This could be due to what was done in the last stage of the program. In this stage, the children (the sample) were trained again on the programs' activities after the long training they have already had, which mainly contributes to the durability of the pre-academic mathematical concepts among those children. In addition to that, the repeated training on the current study's dimensions in various ways (activities) enabled the children to master them. All the above mentioned points helped to keep the effect of the program after its end and during the follow-up period. It also helped to avoid any setback after the end of the program based on the guided discovery learning method.

By reviewing, analyzing and interpreting the study results, the following can be concluded;

- The clear improvement of the study sample's performance on the different dimensions of the pre-academic mathematical concepts' scale (the pre-number concepts, classification concepts and order and seriation concepts) after being subjected to the study's program which is based on the guided discovery learning method to achieve its goal.

- The clear improvement in the performance of the study sample in terms of acquiring some language skills (such as the ability to pronounce the shapes' names, numbers...etc.).

\section{Recommendations}

1) The necessity of guiding and training all the teachers of the disabled child on the various teaching methods that suit the characteristics and meet the demands of this category.

2) Training the teachers of the elementary stage, whether teaching ordinary or intellectually disabled children, on all the mathematical skills that can be provided to children and on the educational methods that fit each skill.

3) Those in charge of teaching children have to pay more attention to the importance of integrating the disabled children's mathematical skills in their curricula using various teaching methods.

4) Conducting campaigns to raise the parents' awareness of the various educational methods that can be easily and appropriately applied to facilitate the children's acquisition of mathematical concepts.

5) Encouraging children to practice the activities without fear or anxious whether in kindergarten or at home.

6) Those in charge of teaching children have to provide them with the programs that attract and draw their attention, in order to create a useful and entertaining learning experience. Computer programs are among the most attractive programs that can be used.

7) The importance of considering the individual teaching style for the members of this category, especially that they still in the primary learning and training stage. This point was followed in this study and proved a notable efficiency.

\section{Acknowledgments}

Essam Abdou Ahmed Saleh is supported with the research grant No (6897-SAR-2017-1-7-F) Deanship of Scientific Research, Northern Border University, Arar, KSA. 


\section{References}

Abdullah, A. (2007). Studies in the Psychology of the Abnormal People, the Abnormal Series (2), pp. 129-135. Dar Al Rashad. Cairo.

Abdullah, E. J. (2013). A Study about the Efficiency of a Training Program in Developing some Mathematical Concepts among the Educable Students with Intellectual Disability in Comparison with the Normal Students with the Same Mental Age. Alzaqaziq: Educational and Psychological studies. The Faculty of Education Journal. Amman. Dar Al- Fikr for Printing and Publishing.

Abdullatief, A. S. (2010). Mathematics Teaching Methods. Dar Al Shorouq. Amman.

Abdulrahman, M. A. (2012). The Efficiency of a Program Based on the Concept of Integration in Developing the Manual Printing Techniques and the Academic Achievement in Mathematics among the Educable Intellectually Disabled Students. PhD Dissertation. Cairo University: Faculty of Specific Education.

Abdulrasol, F. (2008). Special Education for Abnormal People. Cairo: The International House for Distribution \& Publishing.

Abdulsamie Muhammed, S. (2005). The Efficiency of Using the Guided Discovering Strategy in Developing the Silent Reading Skill among Students with Learning Difficulties in the Primary Stage in the Kingdom of Saudi Arabia. Published Paper. The College of Education for Female Teachers. Kingdom of Saudi Arabia.

Abuzaid Najdi, S. (2001). Programs and Methods of Educating the Disabled Child in the Pre-School Stage. Cairo.

Almajdi, H. (2001). The Methods and Skills of Kindergarten Children (p. 168). Al Falah Bookshop Distribution \& Publishing, Kuwait.

Alnajdi, A. (2003). Modern Ways, Methods and Strategies of Teaching Science. Dar Al Fikr Al Alarbi.

Alqathafi, R. M. (2001). The Educational Psychology. The Modern University Office.

Alsaid, A. A. (2006). The Educational Activities for Children with Special Needs (p. 81). Anglo-Egyptian Bookshop. Cairo.

Alshahrani, A. (2004). Teaching Science in the Public Education (2nd ed.). Al-Ryadh. King Fahad Library.

Browder, D. M., \& Spooner, F. (2006). Teaching Language Arts, Math \& Science to Students With Significant Cognitive Disabilities. Baltimore: Paul H. Brookes Publishing Co.

Butros, H. B. (2007). Developing the Kindergarten Child's Scientific and Mathematic Concepts. Amman, Dar Al Massira for Publishing, Printing \& Distributing.

Carin, A. A. (1993). Teaching Science Through Discovery Macmillan Publ. Comp. New York.

Cavanagh, S. (2008). Playing Games in Classroom Helping Pupils Grosp Math. Academic Search Complete, 27, 10.

Cihak, D. F., \& Grim, J. (2008). Teaching Students with Autism Spectrum Disorder and Moderate Intellectual Disabilities to Use Counting-On Strategies to Enhance Independent Purchasing Skills. Research in Autism Spectrum Disorders, 2(4), 716-727. https://doi.org/10.1016/j.rasd.2008.02.006

Clements, D. H., \& Sarama, J. (2005). Building Math Through Every Day. Early Childhood Today, 19(4), 50-57.

Crookshank, F. G. (1971). Educating the Talented and the Retarded. Translated by Yousif Mikhaiel Asad. Cairo: Anglo-Egyptian Bookshop.

Dejonckheere, P. J. N., Desoete, A., Fonck, N., Roderiguez, D., Six, L., Vermeersch, T., \& Vermeulen, L. (2014). Action-Based Digital Tools: Mathematics Learning in 6-Year-Old Children. Electronic. Journal of Research in Educational Psychology, 12(1), 61-82. https://doi.org/10.14204/ejrep.32.13108

Elia, I., \& Evangelou, K. (2014). Gesture in a Kindergarten Mathematics Classroom. European Early. Childhood Education Research Journal, 22(1), 45-66. https://doi.org/10.1080/1350293X.2013.865357

Goals, L. (2008). Disability Bolicy Collaboration, 110th Congress, American Association on Mental Retardation.

Hasan Hanafi, A. (2006). The Efficiency of Using Multiple Teaching Methods in the Lights of the Discovering Strategy to Develop some Artistic Concepts among the High School Students. MA Thesis. Faculty of Fine Arts, Helwan University, p. 85.

Haugland, S. W. (2000). What Role Should Technology Play in Young Children's Learning?, Part 2, Early 
Childhood Class-rooms in the 21st Century. Using Computers to Maximize Learning Young Children, 55(1), 12-18.

Hussien, M. H. A. (2013). The Efficiency of Using the Supermarket Mathematics in Developing some Mathematical Concepts and Skills among Kindergarten Children in the lights of the "National Standards for Kindergarten". MA Thesis. Tanta University. Faculty of Education. pp. 38-40.

Iliev, N., \& D'Angelo, F. (2014). Teaching Mathematics through Multicultural Literature. Teaching Children Mathematics, 20(7), 452-457. https://doi.org/10.5951/teacchilmath.20.7.0452

Kroesbergen, E. H., \& Van Luit, J. E. H. (2003). Mathematics Interventions for Children with Special Educational Needs. A Meta-Analysis Remedial and Special Education, 24, 97-114. https://doi.org/10.1177/07419325030240020501

Labieb, R. (1982). The Growth of Scientific Concepts. Cairo: Anglo-Egyptian Bookshop.

Mahmood Fawzi, Y. (2002). A Suggested Program on Art Education's Activities to Develop the Positive Attitude Toward Reading among Children. PhD Dissertation. Faculty of Fine Arts, Helwan University. Zahra Al Sharq Bookstore.

Mahmoud, S. M., \& Suha, A. A. (2002). The Efficiency of Using Peer- Teaching Strategy in Developing some Daily Mathematical Concepts among the Children with Intellectual Disability. Published Articles. p. 7.

Milo, B. F., Seegers, G., Ruijssenaars, W. A. J. J. M., Vermeer, H. J. (2004). Affective Consequences of Mathematics Instruction for Students with Special Needs. European Journal of Special Needs Education, 19(1), 49-68. https://doi.org/10.1080/0885625032000167142

Moawadh, A. A. (2002). Educating Children with Intellectual Disabilities. Cairo: Dar Al Fikr Al Alarbi.

Mohammad, A. N. (2006). The Role of Music Activities in Enhancing the Kindergarten Child's Ability to Understand some Mathematical Concepts. PhD Dissertation. Alexandria University. Faculty of Kindergarten.

Mohammed, S. M. (2007). A Program to Enable the Normal Students and Students with Hearing Impairment in Kindergarten to Acquire Some Mathematical Concepts. PhD Dissertation. Ain Shams University: Institute of Postgraduate Childhood.

Mories Fahiem, N. (2010). A Recreational Motor Program to Develop the Numerical Skills and General Motor Growth among the Intellectually Disabled Children Aged from 9-14. MA Thesis. Faculty of Physical Education for Girls. Helwan University.

O'Hearn, K. (2007). Mathematical Skill in Individuals with Williams Syndrome: Evidence from a Standardized Mathematics Battery, Laboratory of Neurocognitive Development, University of Pittsburgh Medical Center.

Ortega-Tudela, J. M., \& Gómez-Ariza, C. J. (2006). Computer-assisted teaching and mathematical learning in Down Syndrome children. Journal of Computer Assisted Learning, 22(4), 298-307. https://doi.org/10.1111/j.1365-2729.2006.00179.x

Sirag, M. (2000). The Efficiency of an Expressive Movement Program Using the Guided Discovery Method in Developing the Pre-School Child's Motor-Creativity. Faculty of Physical Education. Tanta University. pp. $38-40$.

Thabit Sama'an, E. (2009). Preparing a Program Using Computer to Enable the Kindergarten Child to Understand the Concepts of Numbers. Sohag: Educational Magazine. Faculty of Education. 25 (January 2009), pp. 125-145.

Thabit, A. M. (2013). An Educational Games Program to Develop some Mathematical Concepts among the Talented Children with Developmental Learning Disabilities and its Effect on Reducing the Impact of Learning Disabilities among the Talented Children. MA Thesis. Cairo University: Faculty of Kindergarten.

Thurlow, M. L., \& Turnure, J. E. (2003) Children's Knowledge of Time and Money: Effective Instruction for the Mentally Retarded. Education and Training of the Mentally Retarded, 12(3), 203-212.

Weiss, I. et al. (2006). Effects of Multimedia Environments on Kinder-garten Children's Mathematical Achievements and Style of Learning. Educational Media International, 43(1), 3-17. https://doi.org/10.1080/09523980500490513

Yahia, K. A., \& Majida, A. (2005). Intellectual Disability. Amman: Dar Wail for Printing. 


\section{Copyrights}

Copyright for this article is retained by the author(s), with first publication rights granted to the journal.

This is an open-access article distributed under the terms and conditions of the Creative Commons Attribution license (http://creativecommons.org/licenses/by/4.0/). 